\title{
The model of the first-year students' adaptation to vocational training: the example of foreign language
}

\author{
Elena M. Galishninkova ${ }^{1}$ and Liliya V. Khafizova ${ }^{1 a}$ \\ ${ }^{1}$ Kazan Federal University, Butlerov street, 4, Kazan, Russia, 420112
}

\begin{abstract}
The paper considers the problem of adaptation of the first-year students to professional activity by means of foreign language. To design the adaptation model, we developed four-block questionnaires to determine students' readiness for adaptation. The experiment resulted in the three groups of students with high, average and low levels of adaptation. Students with low level of adaptation become the target of our research. To remove the difficulties in studying a foreign language by the third group of students, an adaptation model was elaborated. Further, we identified the conditions for the effective implementation of the adaptation model of students to vocational training. In our view, these pedagogical conditions promote a more "sparing" transition of students to their main function as first-year students and increase the level of foreign language learning as well as improve the educational indicators.

Keywords: adaptation; vocational training; adaptation model; foreign language; communicative competence; component; extramural work of students; motivation.
\end{abstract}

\section{Introduction}

One of the fundamental conditions for the successful preparation of competitive professionals at the university is to develop students' interest in obtaining qualified knowledge, skills and competencies. To fulfill this condition, it is necessary to lay the foundations of expertise during the years of attendance in the university, to set up the need and readiness for continuous self-education in a rapidly changing economic environment. In this regard, the problem of future specialist's adaptation to the exercise of profession is brought to the forefront. It is from such specialists that a high level of activity, independence, flexibility, and the ability to quickly orient oneself to any environment are expected. At the same time, the development of international relations, the intensification of business contacts contribute to the demand for specialists who are fluent in a foreign language. The problem of training graduates with knowledge of foreign languages is conditioned by the social order of the society and is currently one of the important tasks in university teaching [8]. In this situation, the issue of adapting students to professional work

\footnotetext{
${ }^{a}$ Corresponding author :ptrlilia2004@mail.ru
} 
with a means of foreign language acquires special significance and seems very relevant to us.

The analysis of scientific sources from different fields of knowledge has shown that adaptation is viewed by scientists from different angles. Adaptation is considered as a central concept in several major social disciplines, for example, G. Simonet emphasizes that there is a growing interest in adaptation in environmental science because of the acceleration of global environmental and socio-economic change [7].

Besides, adaptation is viewed by scientists $[6,9]$ from the perspective of sociology and psychology. It is also considered within the social, cultural and historical aspects [2].

While reviewing scientific sources, we came to the conclusion that in general there are some works devoted to various problems of adaptation in higher educational institutions [3, 4 and 1] and at the same time there are no scientific researches devoted to the first-year student's adaptation to vocational training on the basis of foreign language.

\section{Method}

For the purpose of our research we used such theoretical methods as theoretical analysis of philosophical, pedagogical, psychological literature on the subject of study, generalization, comparison, projection as well as such empirical method as the method of included monitoring and peer review, interviews, questionnaires, discussion, pedagogical experiment, the quantitative analysis of the results of the experiment.

\subsection{Participants}

The participants of the experiment were 124 first-year students of 2016-2017 academic year (the fall semester).

\subsection{Procedure}

Four block questionnaires to determine students' readiness for adaptation were developed. The obtained data was processed by the method of incidence of correspondences, when for each "effect" the frequency of its finding in all reviews was calculated. These blocks are: 1) motivating component of cognitive activity; 2) motivational and emotional block; 3) motivational and communicative block (as an important part of communicative competence),4) motivational activity block.

\section{Discussion}

In modern Russia, intensive studies of the adaptation of young people are conducted at different levels in philosophy, pedagogics and psychology emphasizing its philosophical, psychological and socio-pedagogical aspects. Based on the analysis of scientific sources, it can be concluded that adaptation is considered in sociology, as a form of human behavior that corresponds to personal qualities. In psychological concepts, adaptation appears as a process of active adjustment of an individual to certain material surroundings, norms and values of the social environment, as an indispensible part of the process of socialization.

The main characteristics of adaptation as a concept are: the process of interaction between the individual and the educational environment, and therefore, change in the lifestyle of the individual in accordance with the requirements of this environment; entry and adaptation to new conditions of the social and educational environment (universityhostel-social environment); acceptance of new social roles, norms and values; readiness to change personal qualities under the influence of the educational process and new external factors. And it is important to note that adaptation covers only the first months of the first semester, so it is advisable to consider it as a process of adaptation, assimilation that takes a relatively short period of time. It is known that the educational process is an organized, interrelated and purposeful activity of students and teachers with the aim to acquire vocationally important competences. Since the first component of this process is its goal, 
the second and, especially important one is its subjects and objects (teacher and student), forming a dynamic "teacher-student" system with the teacher having a leading role. The third component is the content of the educational process. The content is carefully selected and analyzed in accordance with the principles of content selection. As the fourth structural component of the educational process, we define its organizational and management unity involving the forms and methods of education and training, the fifth component is pedagogical diagnostics - testing knowledge and skills; expert assessments and characteristics. The sixth structural component of the educational process is extramural work of students, since public life is the most important factor in students' successful socialization.

In the process of mastering a foreign language for specific purpose, students gradually acquire knowledge and skills of professional speech behavior, ethical norms in various professional communications, they elaborate from artificially created situations to a natural professional speech, which determines the building of professional and communicative competence in foreign language. The content of teaching foreign languages to students of economic faculties should be aimed at their training as competitive specialists, which is ensured by a whole set of competences, among which a foreign language professional communicative competence acquires special significance. For the first-year students, at the very first stage of education, we consider it important to determine the "frontiers" of the cognitive aspect and the degree of readiness (motivation) for foreign communication as a first level of professional communicative competence (the skill of speaking in another language). Such "frontiers" and degree of readiness were determined on the basis of an analysis of expert assessments.

\section{Findings}

The responses were distributed by blocks. The following results were obtained: 1st block (motivating component of cognitive activity) - "I have no difficulties in learning a foreign language" (28\%), "I have small difficulties with a foreign language" (39\%), "Learning a foreign language causes me great difficulties"(33\%). Since emotions are closely related to the motivational-cognitive component (knowledge varies and enriches which leads to the change in person's emotions and all levels of the language contain an emotional component [5], we singled out 2 nd block (motivational and emotional) where the responses were - "I am interested in learning a foreign language" (36\%), "I learn a foreign language to get a positive grade" (47\%), "I'm not interested in studying a foreign language" (17\%). 3rd block - motivational and communicative (as an important part of communicative competence) that implies readiness for communication in foreign language classes was determined by students in accordance with the following parameters: "I try to communicate, I do it with pleasure" $(68 \%)$, "I try to communicate on demand, as much as necessary" (25\%), "I cannot speak English at all" (7\%). In addition, we singled out a motivational activity block, which is related to the above-mentioned form of human behavior, which manifests itself most clearly in the desire and willingness of students to participate in certain tasks both during classroom and extracurricular activities, for example "to make a video clip on a certain topic with own soundtrack" $(42 \%$ of respondents expressed their eagerness to perform the task), "to prepare and deliver a report on the topic" (23\% of respondents), "to take part in extracurricular activities (English song party, thematic quiz, mini contest" (12\%), while $23 \%$ ignored the tasks. Thus, during the ascertaining experiment, three groups of students were identified:

1 st group - having a sufficiently high level of adaptation- $44 \%$ of respondents

2 nd group - with an average level of adaptation - $30 \%$ of respondents

3 rd group - low level of adaptation - $26 \%$ of respondents

The third group is the object of our study 
To build an educational experiment, we designed an adaptation model of first-year students to vocational training by means of a foreign language. In general, the design method is practical or theoretical manipulation of the object in which the object under study is replaced by a natural or artificial analogue, through its research we penetrate into the object of cognition. Consequently, the model is an analog of the object of investigation. When designing a model, we have the opportunity to present this or that area of research in the form of a structure, determine its components, their characteristics and relationships, and monitor model's functioning. The obtained results will enable to determine the significance of the created model (environment), to choose the vector of its improvement, to predict the expected result. Accordingly, the goal of creating a theoretical model of vocational adaptation by means of a foreign language is the readiness of students of the economic faculties to professional work, overcoming difficulties in the new educational environment. To construct this model, we will rely on the components of the educational process identified and the above-mentioned components. The theoretical model is based on the following principles: scientific, professional orientation and interdisciplinarity, individualization of teaching, close interaction and mutual understanding between students and teachers.

When designing the model, we incorporate in its structure the basic components of teaching and educational process in the discipline of a foreign language: - target (consistent implementation of the revised goals and objectives), informative (informative content that means professional content in a foreign language and functional originality), activityoperational (methodical and technological mechanisms for the realization of educational tasks: ways, means of teaching, forms of organizing cognitive activity), ethical-behavioral (norms and rules of behavior, and the interaction of applicants- students both in the group and with the faculty), the diagnostic component (controlling and adjusting) (Figure1).

All the elaborated components of the model are designed on the basis of the discipline "Foreign Language". The main objective of studying "Foreign language" as an academic subject in the economics departments of the university is to possess a foreign language at the level that is sufficient for business communication in the framework of the selected profile and to build an individual development pathway, i.e., shaping of professional communicative competence in foreign language. The so-called framework of the selected profile is, in fact, vocational orientation of training, including conceptual and terminological apparatus of the future job, knowledge in the area of interest relying on interdisciplinary links, main categories and ideas, as well as studying some specifics related to the economics, for example, figures, graphs, diagrams, etc. and their description.

As the components of the content of language training in the first year, we consider

- means of communication (grammatical, lexical, stylistic, country knowledge);

- knowledge and skills acquired in the course of training and allowing the use of the language;

- general and professional themes and situations for oral and written communication.

Given the fact that some students come with a fairly high proficiency level and do not encounter any difficulties with adaptation, we shifted our attention to the category of students with a low level of adaptation in accordance with the data of ascertaining experiment. This includes the students from rural localities, students who are not motivated to learn a foreign language; students who came from neighboring countries. Based on our experiment and for effective adaptation process by means of a foreign language for this category of students, we developed the following (implementation) mechanisms: a) placement test which enables to divide students into groups according to the level of language proficiency; b) spiral learning during the first two months, based on the revision of school material and gradual expansion along the line - grammar, vocabulary, communication; c) "immersion" of yesterday's applicants in the student environment by using such teaching aids as preparing and viewing video clips, getting to know the city, the 
university, introducing and communicating with classmates, creating a friendly atmosphere in class, shifting the focus on topics close to yesterday's schoolchildren interests - My native city, My country, The main industries of my country; d) work with the so-called international words (economy, banking, management, marketing, company) e) work with the conceptual-terminological apparatus employing word formation exercises - to consumeconsumption- consumer, consumer goods; to employ-employer-employee - employmentunemployment; f) work with "group of words" - antonyms and synonyms - goodscommodity, items, product; to fall, to go down, to drop, to rise-to-fall, to increase- to decrease: g)massive open online courses (MOOC) designed by teachers of the foreign language department - Job hunting, Great Britain, etc. with lexical, communicative material, tests and audio-visual training tools on relevant topics; $h$ ) development of communication skills through games - "your question - my answer", interviewing fellow students on different topics (question-answer system), organizing mini-dialogues and minispeeches, role-playing games.

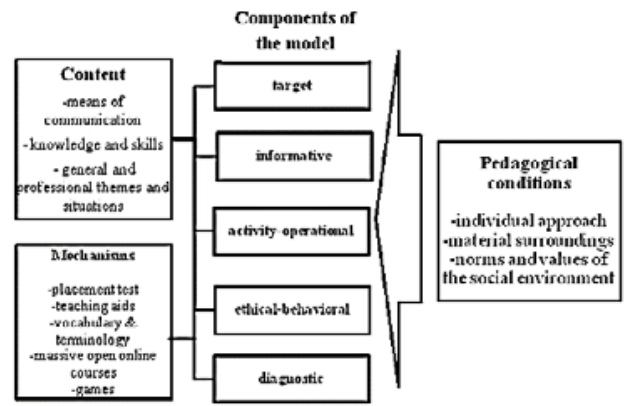

Fig.1. The model of the first-year students' adaptation to vocational training

When solving the problem of adaptation, we do not focus not on the whole "body" of students or a group of students, we pay attention to each of them, taking into account his/her individual characteristics, his/her level of preparedness. Hence, one of the conditions for the effective implementation of the adaptation model of students' to vocational training is the requirement for the teacher to follow an individual approach to each student, which implies, as already mentioned, a form of human behavior that corresponds to personal qualities, that is, 1) personality qualities of students: interests and motives (with the motivation for vocational training, learning a foreign language dominating), traits (activity, consciousness, responsibility, proactivity, the desire for independence, or the purposefulness of an individual or indifference) and temperament (mental ballast, activity, stress-resistance, impulsiveness, sensitivity, vulnerability); 2) the level of intellectual development and cognitive interests (sustained attention, developed imagination, greater integration of memory, the ability to process body of information, to clearly state one's thoughts, focus on the profession and learning a foreign language); 3) independence in the academic work - to make records, compose a mind-map based on the text read, work with reference sources, readiness for self-improvement. It is easier to take into account these parameters for teachers of a foreign language, since the number of hours devoted to this subject (6 hours a week) allows you to meet with them more often and work closely (the learning cycle is 10 - 14 people) both during classes and out-of-class activities (English days, mini-conferences, English language contests, quizzes, Christmas carols party, etc.)

The second condition for the effective implementation of the named model, as we noted above on the basis of the analysis of the scientific literature, is a process of active adjustment of an individual to certain material surroundings, norms and values of the social environment, as an indispensible part of the process of socialization. These certain material 
surroundings and the social environment are created on the basis of the discipline "Foreign Language", namely the creation of a local foreign language environment as part of the educational space, which in turn has a large measure of complexity and includes integrated content of curricula and disciplines, interdisciplinary connections, interaction of traditional and innovative technologies, material and technical base, provides for a close interaction of teachers and students. The teacher of a foreign language, especially if he/she is also the advisor of the group is fully able to carry out psychological and pedagogical support of adaptation. Extracurricular work in a foreign language (song contests, poster contests, watching movies etc.) plays a big role in the process of adaptation of first-year students to vocational learning, as it provides a wide range of development tools for their foreign language potential, cognitive interest, creativity and professional motivation.

Thus, the implementation of the adaptation model of first-year students to professional activity by means of a foreign language on the basis of fulfilling certain pedagogical conditions has made it possible to "build a bridge" that promotes a more "sparing" transition of students (43 students of the above category) to their main function as a first year student.

From the first block (cognitive), the following responses were received (they are selected already from the category defined above - 43 students of experimental groups): by parameters - means of communication - lexical and grammatical aspects were taken. In the experimental group - in lexics - $47 \%$ improved results, in control group - $16 \%$, in grammar - experimental group - $38 \%$, control - $12 \%$.

By parameters - knowledge, skills and abilities that allow using the language - simple monologues and dialogues, the ability to ask and answer questions - the experimental group showed $29 \%$, the control group - $11 \%$.

By the topics and situations of general and professional oral and written communication, the results turned out to be more than modest, although there is a clear improvement in results compared to the control group - a summary of the main idea of the read text on the topic or a brief retelling - 34\% versus 6\% respectively (Figure 2).

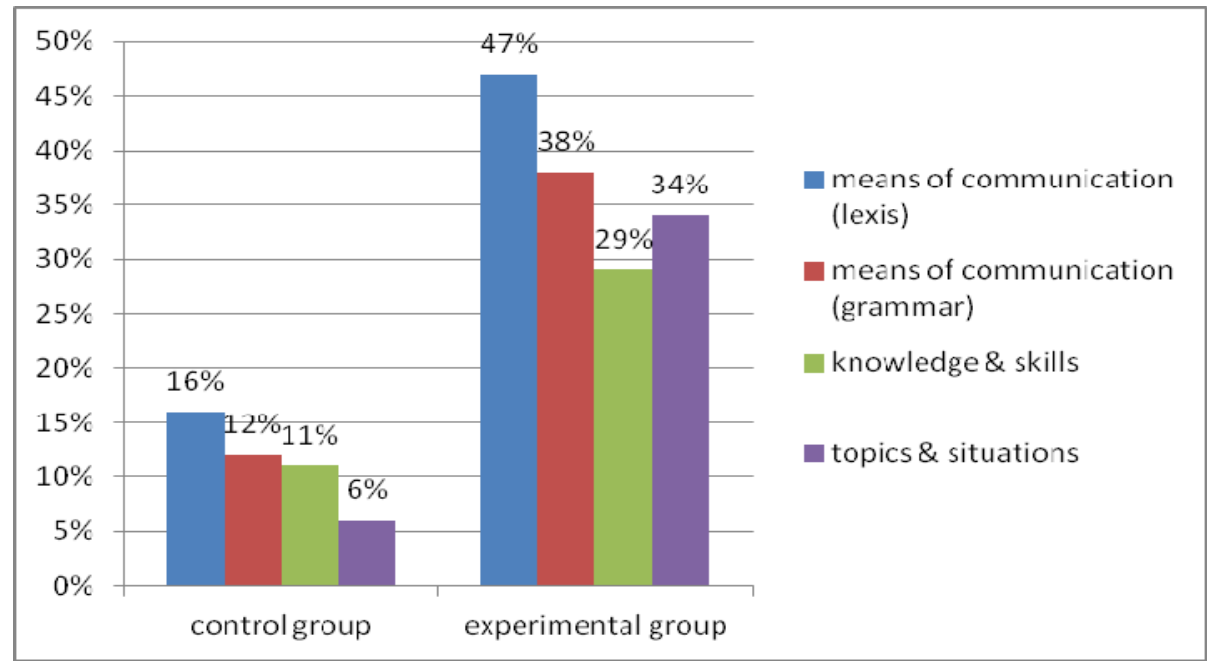

Fig. 2. Results of the ascertaining (control group) and formative (experimental group) experiments

\section{Conclusion}

The process of first year student's adaptation to vocational training by means of foreign language in higher education establishments will be effective if: 
- to introduce adaptation model that consists of target, informative, activity-operational, ethical-behavioral, the diagnostic components

- to employ the implementation mechanisms

- to meet appropriate pedagogical conditions

The research resulted in the development of adaptation model, the mechanisms and conditions for its implementation. These contribute to effective inclusion of low-achieving students into educational environment by means of a foreign language.

\section{References}

1. Bathmaker, A.-M. \& Avis, J. "How do i cope with that?" the challenge of 'schooling' cultures in further education for trainee FE lecturers. British Educational Research Journal, 33(4), 509-532., (2007).

2. Baumeister, R. F \& Muraven, M. Identity as adaptation to social, cultural, and historical context. Journal of Adolescence, 19, 405-416., (1996). https://pdfs.semanticscholar.org/6fd3/b47efab8c3b1740e911c58fa729f4a71a3a9.pdf/

3. Cameron, K. S. Organizational adaptation and Higher education. Journal of Higher Education, 55(2), 122-144., (1984).

4. Figuera, P. \&Torrado, M. The transition to university of at-risk groups in Spain: The case of students from vocational education and training. Revista de Cercetare si Interventie Sociala, 49(6), 23-40., (2015).

5. Goleman, D. The Emotional Intelligence: Why it can matter more than IQ? Bentam Books., (1997).

6. Jakubowicz, A. Psychological adaptation In Encyclopediae Universalis. 247-250., (2002).

7. Simonet, G. "The concept of adaptation: interdisciplinary scope and involvement in climate change", S.A.P.I.EN.S [Online], 3.1 | (2010)., http://sapiens.revues.org/997.

8. Solodkova Irina M. \& Ismagilova Liliya R. Teaching English as a second language: an extent of socio-cultural knowledge. Psychology and psychiatry, sociology and healthcare, education conference proceedings, 1 (III), 1019-1025., (2016)

9. Taché, A. L'adaptation : un concept sociologique systémique. Éditions L'Harmattan,. (2003). 